Acta Crystallographica Section B

Structural Science, Crystal Engineering and Materials

ISSN 2052-5206

\section{Marco Saccone, ${ }^{\mathrm{a}}$ Giancarlo Terraneo, ${ }^{a *}$ Tullio Pilati, Gabriella Cavallo, ${ }^{\text {a* }}$ Arri Priimagi, ${ }^{b} *$ Pierangelo Metrangolo ${ }^{\mathrm{a}}$ and Giuseppe Resnati $^{\mathbf{a}}$}

aNFMLab-DCMIC 'Giulio Natta', Politecnico di Milano, Via L. Mancinelli 7, IT-20131 Milano, Italy, and ${ }^{\mathbf{b}}$ Department of Applied Physics, Aalto University, PO Box 13500, FI-00076 Aalto, Finland

Correspondence e-mail: giancarlo.terraneo@polimi.it, gabriella.cavallo@polimi.it, arri.priimagi@aalto.fi

\title{
Azobenzene-based difunctional halogen-bond donor: towards the engineering of photoresponsive co-crystals
}

Halogen bonding is emerging as a powerful non-covalent interaction in the context of supramolecular photoresponsive materials design, particularly due to its high directionality. In order to obtain further insight into the solid-state features of halogen-bonded photoactive molecules, three halogenbonded co-crystals containing an azobenzene-based difunctional halogen-bond donor molecule, $(E)$-bis(4-iodo-2,3,5,6tetrafluorophenyl)diazene, $\mathrm{C}_{12} \mathrm{~F}_{8} \mathrm{I}_{2} \mathrm{~N}_{2}$, have been synthesized and structurally characterized by single-crystal X-ray diffraction. The crystal structure of the non-iodinated homologue (E)-bis(2,3,5,6-tetrafluorophenyl)diazene, $\mathrm{C}_{12} \mathrm{H}_{2} \mathrm{~F}_{8} \mathrm{~N}_{2}$, is also reported. It is demonstrated that the studied halogen-bond donor molecule is a reliable tecton for assembling halogenbonded co-crystals with potential photoresponsive behaviour. The azo group is not involved in any specific intermolecular interactions in any of the co-crystals studied, which is an interesting feature in the context of enhanced photoisomerization behaviour and photoactive properties of the material systems.

\section{Introduction}

According to a very recent IUPAC definition (Desiraju et al., 2013), 'A halogen bond occurs when there is evidence of a net attractive interaction between an electrophilic region associated with a halogen atom in a molecular entity and a nucleophilic region in another, or the same, molecular entity'. Nowadays, the halogen bond is well established in crystal engineering (Metrangolo et al., 2005; Metrangolo, Resnati et al., 2008; Troff et al., 2013) and its exploitation has allowed for the design of a great variety of systems with quite different topologies, such as discrete adducts, and one-, two- or three-dimensional networks with various connectivities (Metrangolo, Meyer et $a l ., 2008)$. Furthermore, it has been shown that the halogen bond plays a role in tuning several interesting properties such as liquid crystallinity (Nguyen et al., 2004; Bruce et al., 2010), anion reception ability (Sarwar et al., 2010; Caballero et al., 2011; Cametti et al., 2012), nonlinear optical response (Cariati et al., 2011), and low- $k$ conductivity (Sgarbossa et al., 2012), as well as in obtaining pharmaceutical co-crystals (Baldrighi et al., 2013). Moreover, due to its distinct characteristics compared with the hydrogen bond, the halogen bond is emerging as a novel design tool for functional supramolecules (Priimagi et al., 2013; Meyer \& Dubois, 2013). In particular, the high directionality inherent to the halogen bond (Cavallo et al., 2010; Politzer \& Murray, 2013) has resulted in highly efficient photoresponsive, azobenzene-based supramolecular complexes.

We have recently shown that halogen-bonded supramolecular polymer-azobenzene complexes undergo efficient light-
Received 6 August 2013

Accepted 23 September 2013 
induced mass transport when exposed to interference irradiation, and found that the directionality of the polymer-dye non-covalent interaction seems to enhance the mass-transport efficiency (Priimagi, Cavallo et al., 2012). We have also designed halogen-bonded low-molecular-weight complexes with a unique capability of combining efficient photoalignment and high photoinduced mass transport (Priimagi, Saccone et al., 2012). These two studies pointed out that the halogen bond is a highly promising non-covalent interaction in the context of photoresponsive materials design. However, examples of azobenzene molecules containing halogen-bond donor groups are scarce $^{\mathbf{1}}$ (Priimagi, Cavallo et al., 2012; Priimagi, Saccone et al., 2012; Bléger et al., 2012; Walter et al., 2013), and clearly a wider set of such molecules is needed in order to elaborate the photoresponsive behaviour and to understand the full potential of halogen-bonded photoresponsive supramolecules. For this reason, we undertook the synthesis of an azobenzene-based difunctional halogen-bond donor molecule denoted as (2), and report herein a series of co-crystallization studies which demonstrate that molecule (2) is an effective tecton for the engineering of co-crystals with potential photoresponsive behaviour.

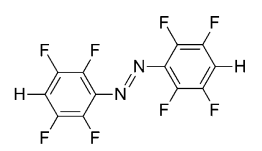

(1)
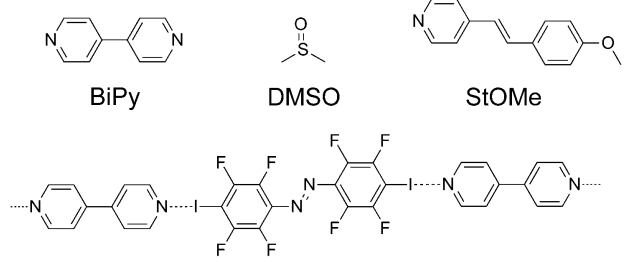

(2):BiPy

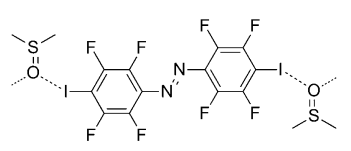

(2):DMSO

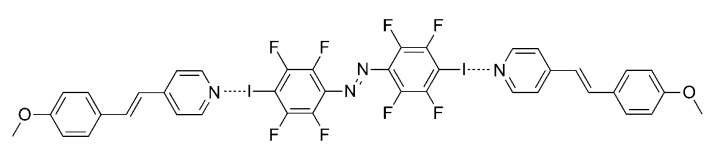

(2):(StOMe) 2

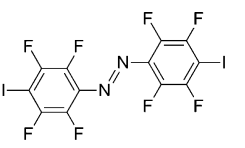

(2)

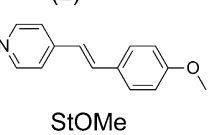

without further purification. Commercial HPLC-grade solvents were used without further purification. Reactions were carried out in oven-dried glassware under an $\mathrm{N}_{2}$ atmosphere. ${ }^{1} \mathrm{H}$ and ${ }^{19} \mathrm{~F}$ NMR spectra were recorded at room temperature on a Bruker AV500 spectrometer, using $\mathrm{CDCl}_{3}$ as the solvent. ${ }^{1} \mathrm{H}$ NMR chemical shifts were referenced to tetramethylsilane (TMS) using the residual proton impurities of the deuterated solvents as a standard reference, while ${ }^{19} \mathrm{~F}$ NMR chemical shifts were referenced to an internal $\mathrm{CFCl}_{3}$ standard. The melting points were determined on a Reichert instrument by observing the melting process through an optical microscope. The attenuated total reflectance Fouriertransform IR (ATR-FTIR) spectra were obtained using a Nicolet Nexus FT-IR spectrometer. The values, given in wavenumbers, were rounded to $1 \mathrm{~cm}^{-1}$ using automatic peak assignment.

\subsection{Synthesis and crystal growth}

Full details of the synthesis and spectroscopic characterization of (1) and (2) are provided in the supporting information. $^{2}$ The synthesis of (2) started from 4-iodo-2,3,5,6tetrafluoroaniline, which was prepared as reported by Meazza et al. (2013). 4-Methoxyl-4'-stilbazole (StOMe) was synthesized according to the procedure reported by Bruce et al. (1988). Single crystals of (1) suitable for X-ray diffraction studies were obtained by slow evaporation from a $\mathrm{CHCl}_{3}$ solution. The crystal of (2):DMSO was obtained after 3 months from a dimethylsulfoxide solution. For the co-crystals, compound (2) and the appropriate halogen-bond acceptor were separately dissolved in THF at room temperature in a 1:1 [for (2):BiPy] or 1:2 [for (2):(StOMe) $)_{2}$ ] stoichiometric ratio. The two saturated solutions were then mixed in a clear borosilicate glass vial, which was left open in a closed cylindrical wide-mouth bottle containing paraffin oil. The solvent was allowed to evaporate slowly at room temperature for $3 \mathrm{~d}$ until good-quality single crystals were formed.

\subsection{Structure determination}

Crystal data, data collection and structure refinement details are summarized in Table 1. Crystals were mounted in inert oil on glass fibres. Data were collected on a Bruker Kappa APEXII CCD diffractometer with Mo $K \alpha$ radiation $(\lambda=0.7107 \AA)$ and a Bruker Kryoflex low-temperature device. For (1), the one $\mathrm{H}$ atom was localized in the difference Fourier map and refined isotropically without restraint. For (2):DMSO, the DMSO molecule lies on a twofold axis. The $\mathrm{H}$ atoms on the one independent methyl group of DMSO were modelled in two orientations rotated from each other by $60^{\circ}$. For (2):(StOMe $)_{2}$, one of the two independent StOMe molecules is modelled as disordered in two orientations, with refined site occupancy 0.767 (1):0.233 (1), and equivalent bond lengths in the two disorder components were restrained to be similar.

\footnotetext{
${ }^{2}$ Supporting information for this paper is available from the IUCr electronic archives (Reference: BI5016).
}

${ }^{1}$ Parallel to this work, it has been reported that crystals of fluorinated azobenzenes are able to undergo photomechanical shape change upon light irradiation (Bushuyev, Tomberg et al., 2013). 
Table 1

Experimental details.

Experiments were carried out at $103 \mathrm{~K}$ with Mo $K \alpha$ radiation using a Bruker APEX-II CCD diffractometer.

\begin{tabular}{|c|c|c|c|c|}
\hline & (1) & (2):DMSO & (2):BiPy & (2):StOMe \\
\hline Chemical formula & $\mathrm{C}_{12} \mathrm{H}_{2} \mathrm{~F}_{8} \mathrm{~N}_{2}$ & $\mathrm{C}_{12} \mathrm{~F}_{8} \mathrm{I}_{2} \mathrm{~N}_{2} \cdot \mathrm{C}_{2} \mathrm{H}_{6} \mathrm{OS}$ & $\mathrm{C}_{12} \mathrm{~F}_{8} \mathrm{I}_{2} \mathrm{~N}_{2} \cdot \mathrm{C}_{10} \mathrm{H}_{8} \mathrm{~N}_{2}$ & $2 \mathrm{C}_{14} \mathrm{H}_{13} \mathrm{NO} \cdot \mathrm{C}_{12} \mathrm{~F}_{8} \mathrm{I}_{2} \mathrm{~N}_{2}$ \\
\hline$M_{\mathrm{r}}$ & 326.16 & 656.07 & 734.12 & 1000.45 \\
\hline$a, b, c(\AA)$ & $\begin{array}{l}6.2100(8), 9.7294(13) \\
\quad 9.2163(13)\end{array}$ & $\begin{array}{l}21.140(3), 10.0766(16), \\
\quad 9.5589(15)\end{array}$ & $\begin{array}{l}5.9388(10), 8.293(2), \\
22.160(4)\end{array}$ & $\begin{array}{l}\text { 5.9758 (6), } 13.998(2), \\
21.989(3)\end{array}$ \\
\hline$\alpha, \beta, \gamma\left({ }^{\circ}\right)$ & $90,98.019(6), 90$ & $90,111.347(12), 90$ & 90, $95.371(12), 90$ & $\begin{array}{l}80.264(12), 88.694(12), \\
81.381(12)\end{array}$ \\
\hline$\mu\left(\mathrm{mm}^{-1}\right)$ & 0.21 & 3.51 & 2.98 & 1.84 \\
\hline Crystal size (mm) & $0.44 \times 0.22 \times 0.16$ & $0.40 \times 0.10 \times 0.03$ & $0.40 \times 0.19 \times 0.10$ & $0.46 \times 0.18 \times 0.06$ \\
\hline \multicolumn{5}{|l|}{ Data collection } \\
\hline Diffractometer & Bruker $A P E X$-II CCD & Bruker $A P E X$-II CCD & Bruker $A P E X$-II CCD & Bruker $A P E X$-II CCD \\
\hline Absorption correction & - & $\begin{array}{l}\text { Multi-scan } S A D A B S \\
\quad \text { (Bruker, 2008) }\end{array}$ & $\begin{array}{l}\text { Multi-scan } S A D A B S \\
\quad \text { (Bruker, 2008) }\end{array}$ & $\begin{array}{l}\text { Multi-scan } S A D A B S \\
\quad \text { (Bruker, 2008) }\end{array}$ \\
\hline$R_{\text {int }}$ & 0.029 & 0.032 & 0.021 & 0.020 \\
\hline$(\sin \theta / \lambda)_{\max }\left(\AA^{-1}\right)$ & 0.833 & 0.595 & 0.800 & 0.757 \\
\hline \multicolumn{5}{|l|}{ Refinement } \\
\hline$R\left[F^{2}>2 \sigma\left(F^{2}\right)\right], w R\left(F^{2}\right), S$ & $0.032,0.104,1.10$ & $0.027,0.065,1.08$ & $0.024,0.050,1.06$ & $0.032,0.073,1.07$ \\
\hline No. of reflections & 2342 & 1662 & 3840 & 9283 \\
\hline No. of parameters & 104 & 137 & 163 & 596 \\
\hline No. of restraints & 0 & 0 & 0 & 509 \\
\hline $\mathrm{H}$-atom treatment & $\begin{array}{l}\text { All H-atom parameters } \\
\text { refined }\end{array}$ & $\begin{array}{l}\mathrm{H} \text {-atom parameters not } \\
\text { refined }\end{array}$ & $\begin{array}{l}\text { H-atom parameters not } \\
\text { refined }\end{array}$ & $\begin{array}{l}\text { H-atom parameters not } \\
\text { refined }\end{array}$ \\
\hline$\Delta \rho_{\max }, \Delta \rho_{\min }\left(\mathrm{e} \AA^{-3}\right)$ & $0.66,-0.24$ & $0.83,-1.19$ & $1.60,-0.77$ & $1.53,-0.64$ \\
\hline
\end{tabular}

Computer programs: APEX2, SAINT (Bruker, 2008), SIR2002 (Burla et al., 2003), SHELXL97 (Sheldrick, 2008), Mercury (Macrae et al., 2008).

\section{Results and discussion}

\subsection{Crystal structure of (1)}

Compound (1) is the bis-deiodinated analogue of (2), which is the main target of this study. The molecule has been crystallized in order to study the determinants of its crystal packing and establish how the introduction of I atoms into its structure, resulting in (2), modifies the crystal packing. Compound (1) crystallizes in space group $P 2_{1} / n$ with the molecule located at the inversion centre, and with the azo group exclusively adopting the trans configuration. The two tetrafluorobenzene rings are not coplanar and the angle between them is $25.3(2)^{\circ}$. The crystal packing is mainly driven by hydrogen bonds between the $\mathrm{H}$ atoms in the para position on the tetrafluorobenzene rings and two $F$ atoms of the adjacent molecules (Fig. 1). This kind of pattern is one of the two possible modes for a bifurcated hydrogen bond (Jeffrey \& Saenger, 1991), namely a three-centred hydrogen bond (THB), where an $\mathrm{H}$ atom which is covalently bonded to an electronegative group (the tetrafluorobenzene ring) is simultaneously hydrogen-bonded to two electron-density donor sites (the F atoms; Rozas et al., 1998). The distances and angles between the donors and the acceptor in (1) are: $\mathrm{H} 4 \cdot \mathrm{F} 3^{\mathrm{i}}=$ $2.56 \AA, \mathrm{C} 4-\mathrm{H} 4 \cdots \mathrm{F}^{\mathrm{i}}=145.5^{\circ} ; \mathrm{H} 4 \cdots \mathrm{F} 4=2.54 \AA, \mathrm{C} 4-$ $\mathrm{H} 4 \cdots \mathrm{F} 4=145.4^{\circ}$ [symmetry code: (i) $\left.\frac{1}{2}-x, \frac{1}{2}+y, \frac{3}{2}+z\right]$.
THBs are quite common in organic molecules (Taylor et al., 1984) and biomolecules (Jeffrey \& Mitra, 1984; Preissner et al., 1991), however, the majority of the electron-density donor

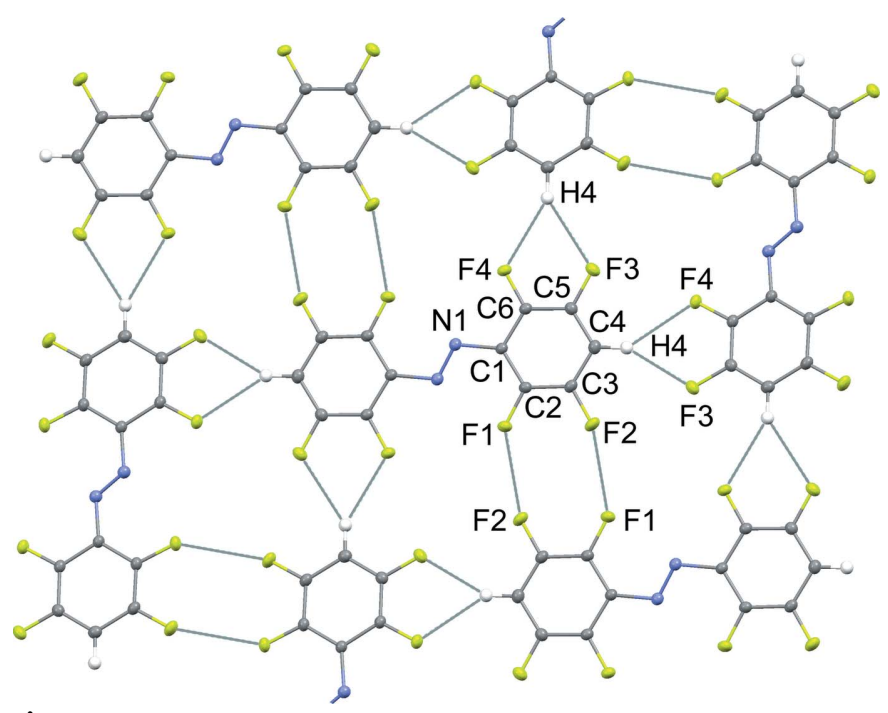

Figure 1

Ellipsoid representation (50\% probability) of a supramolecular layer in (1) assembled by three-centred hydrogen bonds and F..F contacts. Colour code: $\mathrm{C}$, grey; $\mathrm{N}$, blue; F, yellow; $\mathrm{H}$, white. Hydrogen bonds and F...F contacts are depicted as grey lines. 
sites are $\mathrm{O}$ atoms. $\mathrm{F}$ atoms involved in THBs are quite rare and in the Cambridge Structural Database (CSD; Allen, 2002) there are only six structures with $s p^{2}$-C-bound $\mathrm{F}$ atoms which are involved in such a supramolecular synthon.

The bifurcated hydrogen bonds in combination with contacts between $\mathrm{F} 1 \cdots \mathrm{F} 2^{\mathrm{ii}}$ [symmetry code: (ii) $2-x, 1-y, 2-z]$ (and its centrosymmetric equivalent) drive the formation of supramolecular corrugated layers that propagate along the [010] direction (Fig. 1). The crystal packing of (1) is further stabilized through weak $C \cdots C$ and $\mathrm{C} \cdots \mathrm{F}$ contacts between adjacent layers (Fig. 2): $\mathrm{C} 6 \cdots \mathrm{C} 6^{\mathrm{iii}}=$ $3.3144(14), \quad \mathrm{C} 3 \cdots \mathrm{F}^{\mathrm{iv}}=3.1620(10)$ and $\mathrm{C} 5 \cdots \mathrm{F} 1^{\mathrm{v}}=$ 3.1101 (10) $\AA$ [symmetry codes: (iii) $1-x,-y, 2-z$; (iv) $\left.\frac{1}{2}+x, \frac{1}{2}-y, \frac{1}{2}+z ;(\mathrm{v})-\frac{1}{2}+x, \frac{1}{2}-y,-\frac{1}{2}+z\right]$.

From the crystal engineering point of view, it is interesting to compare the supramolecular arrangement seen in (1) with those observed in the related fully hydrogenated and fully fluorinated azobenzenes. The unit-cell parameters of transazobenzene have been known since 1939 (de Lange et al., 1939) and several research groups have studied its solid-state structure in detail (Brown, 1966; Harada \& Ogawa, 2004). In all crystal structures of trans-azobenzene reported in the CSD, the unit cells contain two independent molecules, both on inversion centres, and the non-covalent interactions responsible for the crystal packing are weak $\mathrm{C}-\mathrm{H} \cdots \pi$ contacts occurring between the aromatic rings (Fig. $3 a$ ). The resulting supramolecular motif is very undulating, and no layer organization is present in the trans-azobenzene crystal structures. The crystal structure of trans-decafluoroazobenzene is also reported in the CSD (Chinnakali et al., 1993). The substitution of $\mathrm{F}$ for $\mathrm{H}$ determines the occurrence of $\mathrm{F} \cdots \mathrm{F}$ contacts between the $\mathrm{F}$ atoms in para and meta positions of two adjacent molecules (Fig. 3b). This motif allows for the construction of ribbons propagating along the molecular long axis, but, even in this case, no layer structure is observed.

Compound (1) is, instead, a hybrid hydrocarbon/fluorocarbon system with a high content of $\mathrm{F}$ atoms and also acidic $\mathrm{H}$ atoms. The F..F synthon in (1) resembles that observed in decafluoroazobenzene, but in the former the non-covalent

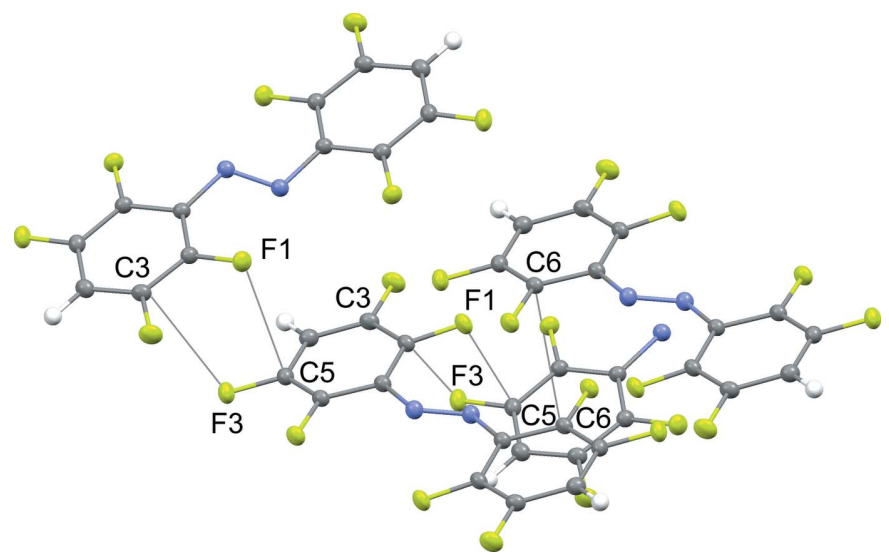

Figure 2

Ellipsoid representation (50\% probability) of the crystal packing of (1). $\mathrm{C} \cdots \mathrm{C}$ and $\mathrm{F} \cdots \mathrm{F}$ interactions are pictured as grey lines. Colour codes as in Fig. 1. interactions involve the ortho and meta $\mathrm{F}$ atoms while in the latter para and meta $\mathrm{F}$ atoms are involved. This geometrical modification of the interacting sites gives rise to the formation of a zigzag supramolecular ribbon rather than a linear chain (Fig. 3c). This difference is clearly due to the presence of the hydrogen-bond donor in the para position of the aromatic ring, which forms a three-centred hydrogen bond with the other two F atoms. The mutual cooperation between THB and F ..F contacts allows for the in-plane connection between the ribbons.

\subsection{Crystal structure of (2):DMSO}

Compound (2) was synthesized so that an azobenzenebased difunctional halogen-bond donor could be used for the self-assembly of photoresponsive co-crystals. Iodine was selected since it is the most polarizable halogen atom and when it is bound to a fluorinated aromatic ring it behaves as a very strong halogen-bond donor (Metrangolo, Resnati et al., 2008). Several solvents and various crystallization techniques were utilized in order to crystallize (2), but only slow evaporation of a dimethylsulfoxide solution afforded goodquality single crystals.

The 1:1 adduct (2):DMSO crystallizes in the space group $C 2 / c$, with the unit cell containing one molecule of (2) lying on the inversion centre, and one DMSO molecule on the twofold rotation axis. In this co-crystal, the diazene derivative is not planar, and the angle formed by the benzene plane and the plane described by atoms $\mathrm{C} 3, \mathrm{~N} 1$ and $\mathrm{N} 1{ }^{\mathrm{i}}$ [symmetry code: (i) $\left.\frac{3}{2}-x, \frac{3}{2}-y, 1-z\right]$ is $28.7(3)^{\circ}$ (Fig. 4), resembling the geometry of molecule (1). The supramolecular assembly is driven by strong halogen bonds between the $\mathrm{O}$ atom of DMSO and the I atoms of (2) (Fig. 4). Both the halogen-bond donor and acceptor molecules behave as bidentate modules, forming a chain of alternating (2) and DMSO molecules. The

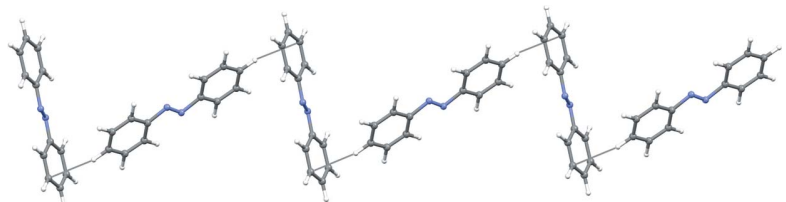

(a)

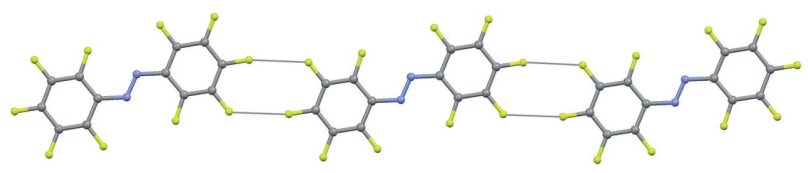

(b)

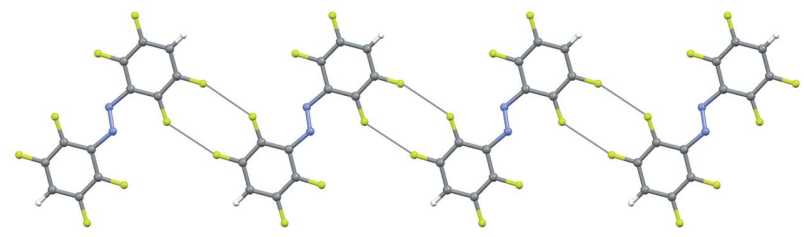

Figure 3

(c)

Supramolecular motifs in (a) trans-azobenzene (CSD code: AZOBEN01; Brown, 1966), (b) trans-decafluoroazobenzene (CSD code: WACHAJ; Chinnakali et al., 1993) and (c) compound (1). C-H $\cdots \pi$ and F $\cdots \mathrm{F}$ contacts are shown as grey lines. 
ability of the $\mathrm{O}$ atom in DMSO to function as an electrondensity donor site has already been proven in several halogenbonded complexes involving either I (Britton, 2003; Ostermeier et al., 2010) or the less polarizable Br (Nayak et al., 2012) as bond donor sites.

The halogen bond is highly directional and capable of translating the geometrical features of the starting modules into the geometrical features of the supramolecular entity. In (2):DMSO, the angle between the two lone pairs on the $\mathrm{O}$ atom imposes the formation of an undulating halogen-bonded chain where the molecules of (2) function as rigid and linear spacers between the bent halogen-bond acceptor sites.

In (2):DMSO the $\mathrm{C}-\mathrm{I} \cdots \mathrm{O}$ halogen bonds are short and directional with the following geometrical parameters: $\mathrm{I} 1 \cdots \mathrm{O} 1^{\mathrm{ii}}=2.630(9) \AA, \mathrm{C} 6-\mathrm{I} 1 \cdots \mathrm{O} 1^{\mathrm{ii}}=178.2(2)^{\circ} ; \mathrm{I} 1 \cdots \mathrm{O} 1^{\mathrm{iii}}=$ $2.926(8) \AA$, $\mathrm{C} 6-\mathrm{I} 1 \cdots \mathrm{O} 1^{\mathrm{iii}}=166.2(2)^{\circ}$ [symmetry codes: (ii) $\frac{1}{2}+x, \frac{1}{2}+y, 1+z$; (iii) $\left.\frac{3}{2}-x, \frac{1}{2}+y, \frac{3}{2}-z\right]$. The I $\cdots \mathrm{O}$ distances correspond to $c a 25$ and $16 \%$ reduction with respect to the

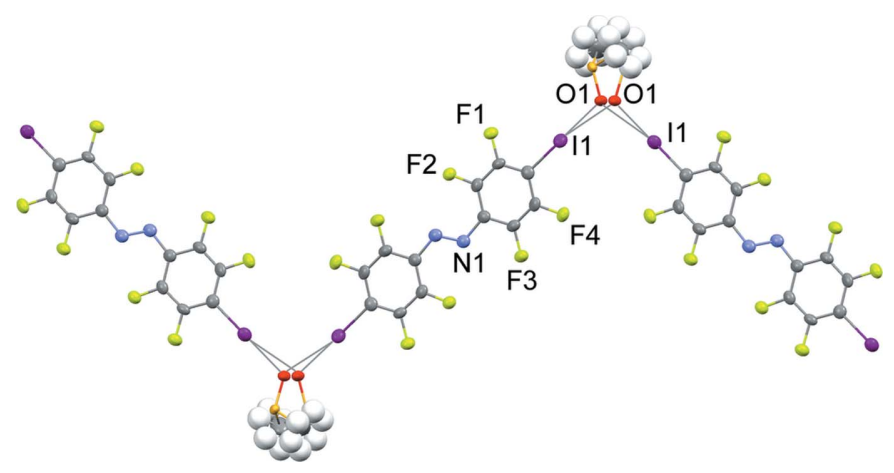

Figure 4

Ellipsoid representation (50\% probability) of the halogen-bonded chain in the (2):DMSO co-crystal. Halogen bonds are shown as grey lines. Colour codes as in Fig. 1; in addition: O, red; S, yellow.

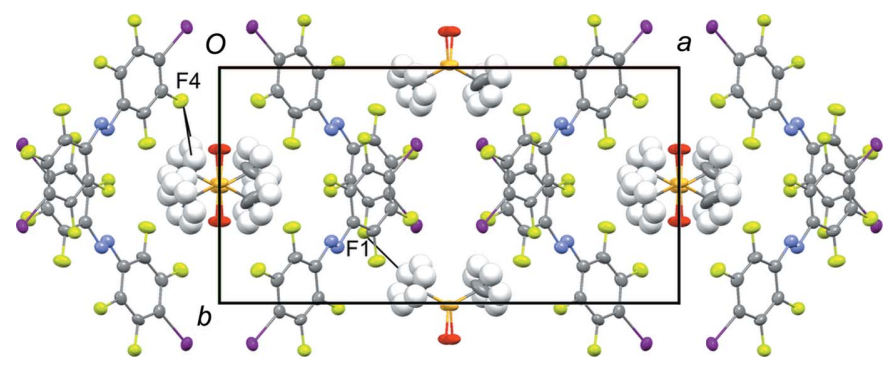

Figure 5

View along the $c$-axis of the channel arrangement in (2):DMSO. The channels are filled with the DMSO molecules. $\mathrm{C}-\mathrm{H} \cdots \mathrm{F}$ contacts are shown as grey lines. sum of the van der Waals radii of the interacting atoms (I,

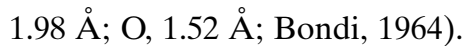

It is interesting to note that in the crystal packing of pure DMSO (Hartmann et al., 1998), the O atoms form four hydrogen bonds leading to the assembly of homomeric layers composed of chains wherein the DMSO molecules are arranged in a head-to-tail fashion. Within the (2):DMSO cocrystal, the halogen bonds replace these hydrogen bonds, resulting in channels that are defined by four molecules of (2) running parallel to the crystallographic $c$-axis, which confine the DMSO molecules (Fig. 5). The channels contain crystallographic inversion centres, but adjacent DMSO molecules within a single channel cannot be related by these centres because the S...S distance [3.266 (1) $\AA]$ is too short. Instead, the DMSO molecules must adopt the $c$-glide relationship, with S...S distances of $\frac{1}{2} c=4.784$ (1) $\AA$. However, the overall distribution of the DMSO molecules in the channels is disordered, and hence the average structure is centrosymmetric. Weak hydrogen bonds between $\mathrm{H}$ atoms of the methyl groups and $\mathrm{F}$ atoms of the aromatic ring stabilize the DMSO molecules within the channels: $\mathrm{F} 1 \cdots \mathrm{H} 7 F^{\mathrm{iv}}=2.56, \mathrm{~F} 4 \cdots \mathrm{H} 7 A^{\mathrm{iii}}=$ 2.50, $\mathrm{F} 4 \cdots \mathrm{H} 7 E^{\mathrm{iii}}=2.62 \AA \quad$ [symmetry code: (iv) $\left.\frac{3}{2}-x, \frac{5}{2}-y, 1-z\right]$.

\subsection{Crystal structure of (2):BiPy}

A confirmation of the very good propensity of molecule (2) to become involved in halogen bonding came from the obtainment of its co-crystal with 4,4'-bipyridine (BiPy), which is a standard difunctional halogen-bond acceptor module. The co-crystal (2):BiPy crystallizes in the space group $P 2_{1} / c$, with both the halogen-bond donor and acceptor units lying on inversion centres. The two interacting modules are ditopic tectons bearing two monodentate interaction sites, i.e. the I atoms for (2) and the $\mathrm{N}$ atoms for $\mathrm{BiPy}$, which pair with each other and form a halogen-bonded adduct with a 1:1 stoichiometric ratio. The supramolecular arrangement is controlled by halogen bonds between the I and $\mathrm{N}$ atoms, leading to the formation of a chain propagating along the [201] direction (Fig. 6). The halogen-bond donor-acceptor distance in the supramolecular chain is 2.8149 (18) $\AA$, corresponding to $c a$ $20 \%$ contraction with respect to the sum of the van der Waals radii for $\mathrm{N}$ and I (Bondi, 1964). The $\mathrm{C} 1-\mathrm{I} 1 \cdots \mathrm{N} 2$ angle is $179.03(7)^{\circ}$, consistent with the expected directionality of the halogen bond (Saccone et al., 2013; Politzer \& Murray, 2013).

Both (2) and BiPy are flat molecules, and their aromatic rings are coplanar. However, along the halogen-bonded chain, the two tectons adopt a non-planar arrangement, with the angle between the tetrafluorobenzene and the pyridyl rings being $72.5^{\circ}$ (Fig. 6). The molecules of (2) and BiPy are connected along the [210] direction by weak hydrogen bonds between the $\mathrm{H}$ atoms on the pyridyl rings and the $\mathrm{F}$ atoms $(\mathrm{C} 7-\mathrm{H} 7 \cdots \mathrm{F} 2, \quad \mathrm{C} 8-$ $\mathrm{H} 8 \cdots \mathrm{F} 3$ and $\mathrm{C} 10-\mathrm{H} 10 \cdots \mathrm{F} 4$; Fig. 7). The geometrical parameters for

Figure 6

Ellipsoid representation (50\% probability) of a halogen-bonded chain in the (2):BiPy co-crystal. Colour codes as in Fig. 1; in addition: I, purple. Halogen bonds are shown as grey lines. 
Table 2

Hydrogen-bond geometry $\left(\AA,^{\circ}\right)$ for (2):bipy.

\begin{tabular}{lllll}
\hline$D-\mathrm{H} \cdots A$ & $D-\mathrm{H}$ & $\mathrm{H} \cdots A$ & $D \cdots A$ & $D-\mathrm{H} \cdots A$ \\
\hline $\mathrm{C} 7-\mathrm{H} 7 \cdots \mathrm{F}^{\mathrm{i}}$ & 0.95 & 2.53 & $3.429(3)$ & 159 \\
$\mathrm{C} 8-\mathrm{H} 8 \cdots \mathrm{F}^{\mathrm{ii}}$ & 0.95 & 2.43 & $3.205(3)$ & 138 \\
$\mathrm{C} 10-\mathrm{H} 10 \cdots \mathrm{F} 4^{\mathrm{iii}}$ & 0.95 & 2.46 & $3.316(3)$ & 150 \\
$\mathrm{C} 11-\mathrm{H} 11 \cdots \mathrm{F}^{\text {iv }}$ & 0.95 & 2.46 & $3.359(3)$ & 158 \\
\hline
\end{tabular}

Symmetry codes: (i) $-x, y+\frac{1}{2},-z+\frac{1}{2}$; (ii) $x,-y+\frac{1}{2}, z-\frac{1}{2}$; (iii) $-x+2, y-\frac{1}{2},-z+\frac{1}{2}$; (iv) $x+1, y, z$.

the hydrogen bonds are reported in Table 2 . These $\mathrm{H} \cdots \mathrm{F}$ contacts generate a supramolecular tape where the alternating halogen-bond donors and acceptors are quasi-coplanar; the angle defined by the plane of the benzene rings in (2) and the plane of the pyridyl rings in $\mathrm{BiPy}^{\mathrm{i}}$ is $1.1^{\circ}$ [symmetry code: (i) $\left.x, \frac{1}{2}+y, \frac{1}{2}-z\right]$. The halogen-bonded chains interact through short $\mathrm{C} \cdots \mathrm{C}$ contacts: $\mathrm{C} 3 \cdots \mathrm{C} 7^{\mathrm{ii}}=3.388(3), \mathrm{C} 8 \cdots \mathrm{C} 8^{\mathrm{iii}}=$ 3.388 (4) $\AA$ [symmetry codes: (ii) $1-x,-\frac{1}{2}+y, \frac{1}{2}-z$; (iii) $1-x,-y,-z]$, while no $\pi-\pi$ interactions are observed. Finally, the chains are also connected by additional $\mathrm{H} \cdots \mathrm{F}$ hydrogen bonds between the ortho $\mathrm{H}$ atom of the pyridyl ring (H11) and the F atom (F1) in the meta position of molecule (2).

\subsection{Crystal structure of (2):(StOMe) $)_{2}$}

StOMe is a very interesting promesogenic molecule. Under the hypothesis that an eventual co-crystal between (2) and StOMe may show interesting photoresponsive liquid crystallinity, we studied the reaction between (2) and StOMe. The

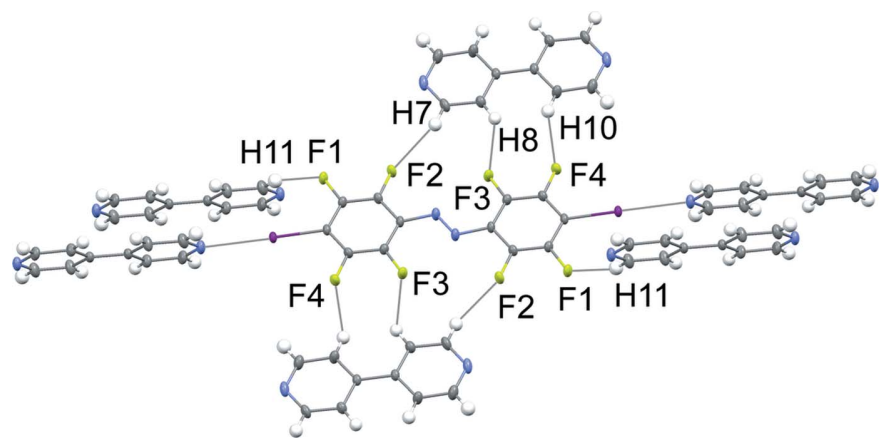

Figure 7

Hydrogen-bonding patterns in the (2):BiPy co-crystal.

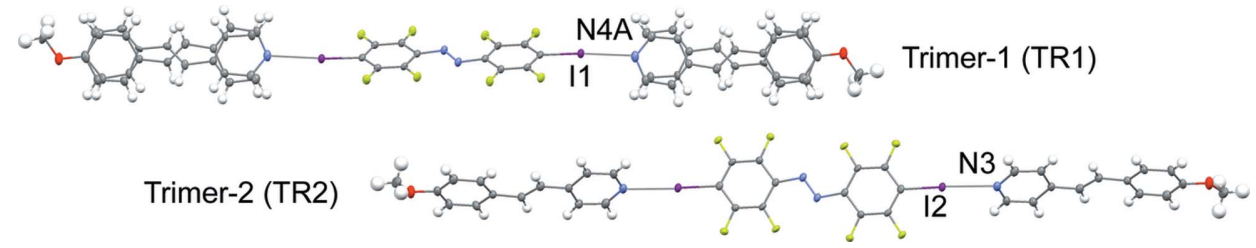

Figure 8

Ellipsoid representation (50\% probability) of the two halogen-bonded trimeric systems in the (2):(StOMe $)_{2}$ co-crystal. The StOMe molecule in TR1 is disordered over two positions [refined ratio 0.767 (1):0.233 (1)]. Atom colour code and halogen bonds are as in Fig. 6.
Table 3

Hydrogen-bond geometry $\left(\AA,^{\circ}\right)$ for $(2):(\mathrm{StOMe})_{2}$.

\begin{tabular}{lllll}
\hline$D-\mathrm{H} \cdots A$ & $D-\mathrm{H}$ & $\mathrm{H} \cdots A$ & $D \cdots A$ & $D-\mathrm{H} \cdots A$ \\
\hline $\mathrm{C} 14-\mathrm{H} 14 \cdots \mathrm{F}^{\mathrm{i}}$ & 0.95 & 2.62 & $3.492(3)$ & 152 \\
$\mathrm{C} 16-\mathrm{H} 16 \cdots \mathrm{F}^{\mathrm{ii}}$ & 0.95 & 2.61 & $3.276(3)$ & 127 \\
$\mathrm{C} 24-\mathrm{H} 24 \cdots \mathrm{F}^{\mathrm{iii}}$ & 0.95 & 2.54 & $3.145(3)$ & 122 \\
$\mathrm{C} 25-\mathrm{H} 25 \cdots \mathrm{F}^{\mathrm{iii}}$ & 0.95 & 2.51 & $3.132(3)$ & 123 \\
$\mathrm{C} 29 A-\mathrm{H} 29 A \cdots \mathrm{F} 2^{\text {iv }}$ & 0.95 & 2.56 & $3.451(3)$ & 156 \\
$\mathrm{C} 32 A-\mathrm{H} 32 A \cdots \mathrm{F} 6$ & 0.95 & 2.59 & $3.503(3)$ & 163 \\
$\mathrm{C} 39 A-\mathrm{H} 39 A \cdots \mathrm{F} 5$ & 0.95 & 2.61 & $3.382(3)$ & 139 \\
\hline
\end{tabular}

Symmetry codes: (i) $-x+1,-y,-z+1$; (ii) $-x+2,-y,-z+1$; (iii) $x+1, y, z+1$; (iv) $x+1, y, z$

two compounds were mixed in THF in a 1:2 ratio, since StOMe is a monodentate halogen-bond acceptor. As expected, the trimeric adduct (2):(StOMe $)_{2}$ was obtained, which crystallized in space group $P \overline{1}$. The unit cell comprises two trimeric complexes labelled hereafter as trimer-1 (TR1) and trimer-2 (TR2; Fig. 8). In the trimers the stilbazole molecules are complexed to (2) through halogen bonds: $\mathrm{I} 1 \cdots \mathrm{N} 4 A / \mathrm{N} 4 B^{\mathrm{i}}=$ $2.812(4), \mathrm{I} 2 \cdots \mathrm{N} 3^{\mathrm{ii}}=2.776(2) \AA$, and $\mathrm{C} 3-\mathrm{I} 1 \cdots \mathrm{N} 4 A / \mathrm{N} 4 B^{\mathrm{i}}=$ $174.71(10), \mathrm{C} 9-\mathrm{I} 2 \cdots \mathrm{N} 3^{\mathrm{ii}}=174.75(10)^{\circ}$ [symmetry codes: (i) $-2+x, y, z$; (ii) $2-x,-y, 1-z]$. Similar to the (2): $\mathrm{BiPy}$ co-crystal, the halogen bonds in (2):(StOMe $)_{2}$ are strong and directional, confirming the general ability of (2) to function as a good halogen-bond donor.

In both trimers the centrosymmetric tetrafluoroaromatic rings are coplanar as also observed in the (2):BiPy co-crystal. The StOMe molecules in TR1 are disordered over two positions that are related by $180^{\circ}$ rotation approximately along the long axis of the stilbazole molecule. Only the stilbazole core is disordered, while the methoxyl group appears to be ordered. Similar to (2):BiPy, the iodotetrafluorobenzene and pyridyl rings of the (2): (StOMe $)_{2}$ trimers are not coplanar, the angles between the planes described by the tetrafluorobenzene and pyridyl rings being $60.9^{\circ}$ in TR1 and $62.5^{\circ}$ in TR2.

Each molecule of (2) is also bound, in the plane defined by the tetrafluoroaromatic rings, to two neighbouring alkoxystilbazole molecules by several weak hydrogen bonds. In TR1 the $\mathrm{F} \cdot \mathrm{H}$ contacts involve the aromatic $\mathrm{H}$ atoms of the pyridyl and benzene rings but not those on the ethylene group. Conversely, in TR2 the hydrogen bonds occur specifically between the $\mathrm{F}$ atoms on the tetrafluorobenzene ring and one aromatic $\mathrm{H}$ atom on the benzene ring, and one $\mathrm{H}$ atom on the ethylene group in StOMe (Fig. 9). The trimers are connected to nearby trimers by additional weak $\mathrm{F} \cdot \mathrm{H}$ interactions that occur out of the plane described by the diazene molecules. Relevant geometrical parameters are reported in Table 3. Moreover, weak $\mathrm{C}-\mathrm{H} \cdots \pi$ contacts between the methoxyl groups and weak $\pi-\pi$ stacking between the tetrafluorobenzene ring and pyridyl or benzene ring of StOMe further stabilize the crystal packing of (2):(StOMe $)_{2}$ (Table 3). 


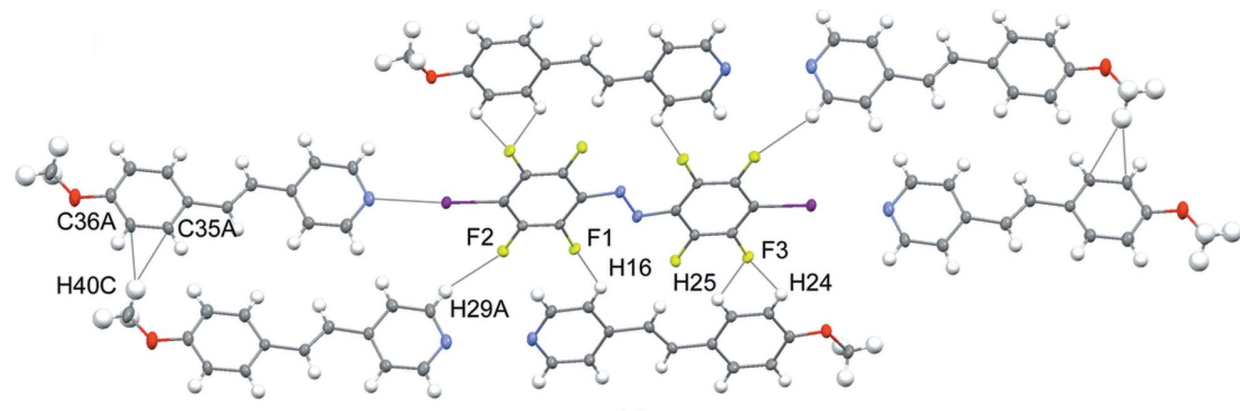

(a)

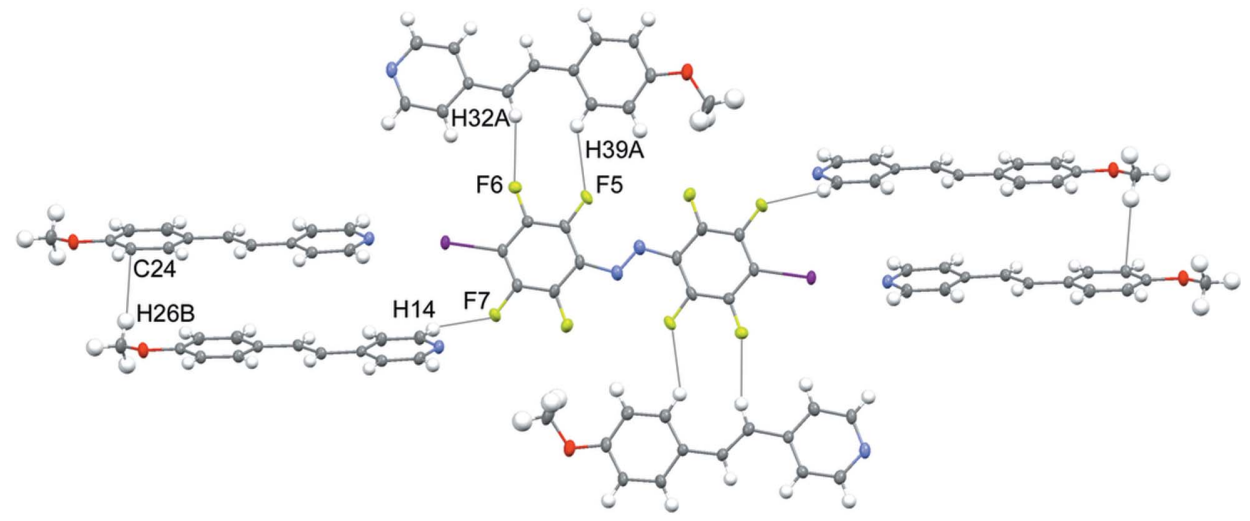

(b)

Figure 9

Hydrogen bonds and $\mathrm{C}-\mathrm{H} \cdots \pi$ contacts in $(a)$ TR1 and $(b)$ TR2. The disorder of the StOMe molecule has been omitted for clarity. Contacts are shown as grey lines.

Alkoxystilbazole molecules have been recently used in the construction of trimeric halogen-bonded liquid crystals (Bruce et al., 2008). In terms of distances and angles between the halogen-bond donor and acceptor, the (2):(StOMe) $)_{2}$ trimers share strong similarity with those reported by Bruce et al. Investigations of the liquid crystalline properties of the (2):(StOMe $)_{2}$ complex are currently in progress.

\section{Conclusions}

In this paper, we have assessed the ability of $(E)$-bis(4-iodo2,3,5,6-tetrafluorophenyl)diazene to be involved in molecular recognition and self-assembly processes through $\mathrm{C}-\mathrm{I} \cdots \mathrm{N}$ and $\mathrm{C}-\mathrm{I} \cdots \mathrm{O}$ supramolecular interactions. The structural studies have shown that the I atoms on the fluorinated diazene molecule (2) function as strong and effective halogen-bond donor sites, interacting with a variety of halogen-bond acceptors and resulting in various supramolecular architectures, i.e. linear or highly corrugated chains as well as discrete adducts. The reported results highlight the potential and versatility of molecule (2) for engineering photoresponsive co-crystals. In particular, (2) has potential in view of photomechanical crystals (Bushuyev et al., 2013) and it may be used to crosslink photoresponsive elastomers non-covalently (Mamiya et al., 2008). Furthermore, in the halogenbonded co-crystals studied here, the azo group is never involved in any specific intermolecular interactions. This feature may enhance the photoresponsive behaviour of (2) due to an easier photoisomerization of the azo group in the crystalline state.

\section{References}

Allen, F. H. (2002). Acta Cryst. B58, 380-388.

Baldrighi, M., Cavallo, G., Chierotti, M. R., Gobetto, R., Metrangolo, P., Pilati, T., Resnati, G. \& Terraneo, G. (2013). Mol. Pharm. 10, 17601772.

Bléger, D., Schwarz, J., Brouwer, A. M. \& Hecht, S. (2012). J. Am. Chem. Soc. 134, 20597-20600.

Bondi, A. (1964). J. Phys. Chem. 68, 441-451.

Britton, D. (2003). Acta Cryst. E59, o1332-o1333.

Brown, C. J. (1966). Acta Cryst. 21, 146152.

Bruce, D. W., Dunmur, D. A., Lalinde, E., Maitlis, P. M. \& Styring, P. (1988). Liq. Cryst. 3, 385-395.

Bruce, D. W., Metrangolo, P., Meyer, F., Pilati, T., Präsang, C., Resnati, G., Terraneo, G., Wainwright, S. G. \& Whitwood, A. C. (2010). Chem. Eur. J. 16, 9511-9524.

Bruce, D. W., Metrangolo, P., Meyer, F., Präsang, C., Resnati, G., Terraneo, G. \& Whitwood, A. C. (2008). New J. Chem. 32, 477-482.

Bruker (2008). APEX2, SAINT and SADABS. Bruker AXS Inc. Madison, Wisconsin, USA.

Burla, M. C., Camalli, M., Carrozzini, B., Cascarano, G. L., Giacovazzo, C., Polidori, G. \& Spagna, R. (2003). J. Appl. Cryst. 36, 1103.

Bushuyev, O. S., Singleton, T. A. \& Barrett, C. J. (2013). Adv. Mater. 12, 1796-1800.

Bushuyev, O. S., Tomberg, A., Friscic, T. \& Barrett, C. J. (2013). J. Am. Chem. Soc. 135, 12556-12559.

Caballero, A., White, N. G. \& Beer, P. D. (2011). Angew. Chem. Int. Ed. 50, 1845-1848.

Cametti, M., Raatikainen, K., Metrangolo, P., Pilati, T., Terraneo, G. \& Resnati, G. (2012). Org. Biomol. Chem. 10, 1329-1333.

Cariati, E., Cavallo, G., Forni, A., Leem, G., Metrangolo, P., Meyer, F., Resnati, G., Righetto, S., Terraneo, G. \& Tordin, E. (2011). Cryst. Growth Des. 11, 5642-5648.

Cavallo, G., Biella, S., Lu, J., Metrangolo, P., Pilati, T., Resnati, G. \& Terraneo, G. (2010). J. Fluorine Chem. 131, 1165-1172.

Chinnakali, K., Fun, H.-K., Shawkataly, O. B. \& Teoh, S.-G. (1993). Acta Cryst. C49, 615-616.

Desiraju, G. R., Ho, P. S., Kloo, L., Legon, A. C., Marquardt, R., Metrangolo, P., Politzer, P., Resnati, G. \& Rissanen, K. (2013). Pure Appl. Chem. 85, 1711-1713.

Harada, J. \& Ogawa, K. (2004). J. Am. Chem. Soc. 126, 3539-3544.

Hartmann, F., Dahlems, T. \& Mootz, D. (1998). Z. Kristallogr. New Cryst. Struct. 213, 639-640.

Jeffrey, G. A. \& Mitra, J. (1984). J. Am. Chem. Soc. 106, 5546-5553.

Jeffrey, G. A. \& Saenger, W. (1991). Hydrogen Bonding in Biological Structures. Berlin: Springer-Verlag.

Lange, J. J. de, Robertson, J. M. \& Woodward, I. (1939). Proc. R. Soc. London Ser. A, 171, 398-410. 


\section{crystal engineering}

Macrae, C. F., Bruno, I. J., Chisholm, J. A., Edgington, P. R., McCabe, P., Pidcock, E., Rodriguez-Monge, L., Taylor, R., van de Streek, J. \& Wood, P. A. (2008). J. Appl. Cryst. 41, 466-470.

Mamiya, J., Yoshitake, A., Kondo, M., Yu, Y. \& Ikeda, T. (2008). J. Mater. Chem. 18, 63-65.

Meazza, L., Foster, J. A., Fucke, K., Metrangolo, P., Resnati, G. \& Steed, J. W. (2013). Nature Chem. 5, 42-47.

Metrangolo, P., Meyer, F., Pilati, T., Resnati, G. \& Terraneo, G. (2008). Angew. Chem. Int. Ed. 47, 6114-6127.

Metrangolo, P., Neukirch, H., Pilati, T. \& Resnati, G. (2005). Acc. Chem. Res. 38, 386-395.

Metrangolo, P., Resnati, G., Pilati, T. \& Biella, S. (2008). Struct. Bond. 126, 105-136.

Meyer, F. \& Dubois, P. (2013). CrystEngComm, 15, 3058-3071.

Nayak, S. K., Terraneo, G., Forni, A., Metrangolo, P. \& Resnati, G. (2012). CrystEngComm, 14, 4259-4261.

Nguyen, H. L., Horton, P. N., Hursthouse, M. B., Legon, A. C. \& Bruce, D. W. (2004). J. Am. Chem. Soc. 126, 16-17.

Ostermeier, M., Berlin, M. A., Meudtner, R. M., Demeshko, S., Meyer, F., Limberg, C. \& Hecht, S. (2010). Chem. Eur. J. 16, 1020210213.

Politzer, P. \& Murray, J. S. (2013). ChemPhysChem, 14, 278-294.

Preissner, R., Egner, U. \& Saenger, W. (1991). FEBS Lett. 288, $192-$ 196.
Priimagi, A., Cavallo, G., Forni, A., Gorynsztejn-Leben, M., Kaivola, M., Metrangolo, P., Milani, R., Shishido, A., Pilati, T., Resnati, G. \& Terraneo, G. (2012). Adv. Funct. Mater. 22, 2572-2579.

Priimagi, A., Cavallo, G., Metrangolo, P. \& Resnati, G. (2013). Acc. Chem. Res. 46, 2686-2695.

Priimagi, A., Saccone, M., Cavallo, G., Shishido, A., Pilati, T., Metrangolo, P. \& Resnati, G. (2012). Adv. Mater. 24, OP345-352.

Rozas, I., Alkorta, I. \& Elguero, J. (1998). J. Phys. Chem. A, 102, 9925-9932.

Saccone, M., Cavallo, G., Metrangolo, P., Pace, A., Pibiri, I., Pilati, T., Resnati, G. \& Terraneo, G. (2013). CrystEngComm, 15, 31023105.

Sarwar, M. G., Dragisic, B., Sagoo, S. \& Taylor, M. S. (2010). Angew. Chem. Int. Ed. 49, 1674-1677.

Sgarbossa, P., Bertani, R., Di Noto, V., Piga, M., Giffin, G. A., Terraneo, G., Pilati, T., Metrangolo, P. \& Resnati, G. (2012). Cryst. Growth Des. 12, 297-305.

Sheldrick, G. M. (2008). Acta Cryst. A64, 112-122.

Taylor, R., Kennard, O. \& Versichel, W. (1984). J. Am. Chem. Soc. 106, 244-248.

Troff, R. W., Mäkelä, T., Topić, F., Valkonen, A., Raatikainen, K. \& Rissanen, K. (2013). Eur. J. Org. Chem. 9, 1617-1637.

Walter, S. M., Jungbauer, S. H., Kniep, F., Schindler, S., Herdtweck, E. \& Huber, S. M. (2013). J. Fluorine Chem. 150, 14-20. 